\title{
Two dimensional echocardiographic diagnosis of situs
}

\author{
JAMES C HUHTA, „ JEFFREY F SMALLHORN, FERGUS J MACARTNEY \\ From The Hospital for Sick Children, Great Ormond Street, London
}

SUMMARY At present there is no reliable method of recognising atrial isomerism by two dimensional echocardiography. We therefore used two dimensional echocardiography to examine 158 patients including 25 with atrial isomerism and four with situs inversus. Particular attention was paid to the short and long axis subcostal scans of the abdomen.

Using the position of the inferior vena cava and the aorta with respect to the spine it was possible to separate those with situs solitus from the others. Two false positives for abnormal situs had exomphalos. In situs solitus the aorta lay to the left of the spine and the inferior vena cava lay to the right. One patient with situs solitus and azygos continuation of the inferior vena cava also had inferior vena cava to right atrial connection. In the four patients with situs inversus the mirror image of the normal pattern was present.

In nine patients with right isomerism the inferior vena cava and aorta ran together on one or other side of the spine. The inferior vena cava, anterior to the aorta at the level of the diaphragm, received at least the right hepatic veins (normal or partial anomalous hepatic venous connection).

Of the 16 patients with left isomerism, 14 had azygos continuation of the inferior vena cava which was visualised posterior to the aorta in all but two. All patients with left isomerism had total anomalous hepatic venous connection to one or both atria via one or two separate veins.

Two dimensional echocardiography therefore provides the means of detecting abnormal atrial situs and of diagnosing right or left isomerism in the great majority of patients, if not all.

Accurate determination of atrial situs is the foundation of a segmental approach to the diagnosis of congenital malformations and malpositions. ${ }^{1-4}$ Many clinical clues are available for the recognition of patients with abnormal situs, and the importance of identifying left and right isomerism has been emphasised by many authors. ${ }^{5-8} \mathrm{~A}$ non-invasive examination such as two dimensional echocardiography which could be used routinely to determine situs would be very useful. At present, the determination of atrioventricular connection by two dimensional echocardiography is speculative and other techniques are necessary to assign atrial situs. ${ }^{8-10}$ Alerted to the presence of abnormal situs, the echocardiographer will pay particular attention to the systemic and pulmonary venous connections.

To investigate the diagnosis of situs by two dimensional echocardiography we examined 158 consecutive patients including 11 who were known to have

^Present address: Texas Children's Hospital, Pediatric Cardiology, 6621 Fannin, Houston, Texas 77030, USA.

Accepted for publication 15 April 1982 abnormal situs. Over this five month period 18 additional patients were diagnosed prospectively as having abnormal situs and were correctly categorised into those with situs inversus, right isomerism, or left isomerism.

The purpose of this study was to consider criteria for the two dimensional echocardiographic assessment of situs. Two questions were considered.

(1) Can two dimensional echocardiography be used accurately to separate patients with abnormal situs from those with situs solitus?

and, if so,

(2) Can those criteria be used further to subdivide the abnormal situs patients into those with situs inversus, right isomerism, and left isomerism?

\section{Subjects and methods}

Between September 1981 and January 1982, 158 consecutive patients had a two dimensional echocardiographic examination at The Hospital for Sick Children, Great Ormond Street, by one of us (JCH or JFS). The ages of the patients ranged from 1 day to 16 
years, with a mean age of 2.9 years. Forty-three per cent were under 1 year of age. A complete examination was performed in each patient, including subcostal, parasternal, apical, and suprasternal views. ${ }^{11}$ Sequential analysis of the anatomy was performed using the terms and definitions suggested by Tynan et al. ${ }^{12}$ Particular attention was paid to the short and long axis subcostal scans of the abdomen and the systemic venous return. In order to recognise absence of the inferior vena cava immediately inferior to the cardiac atria it was important to recognise positively the crus of the diaphragm, which could superficially resemble a venous structure. During this time, 11 patients previously diagnosed as having abnormal situs were recalled and also examined by two dimensional echocardiography in the same way without knowledge of the type of situs abnormality.

Patients excluded were those without confirmation

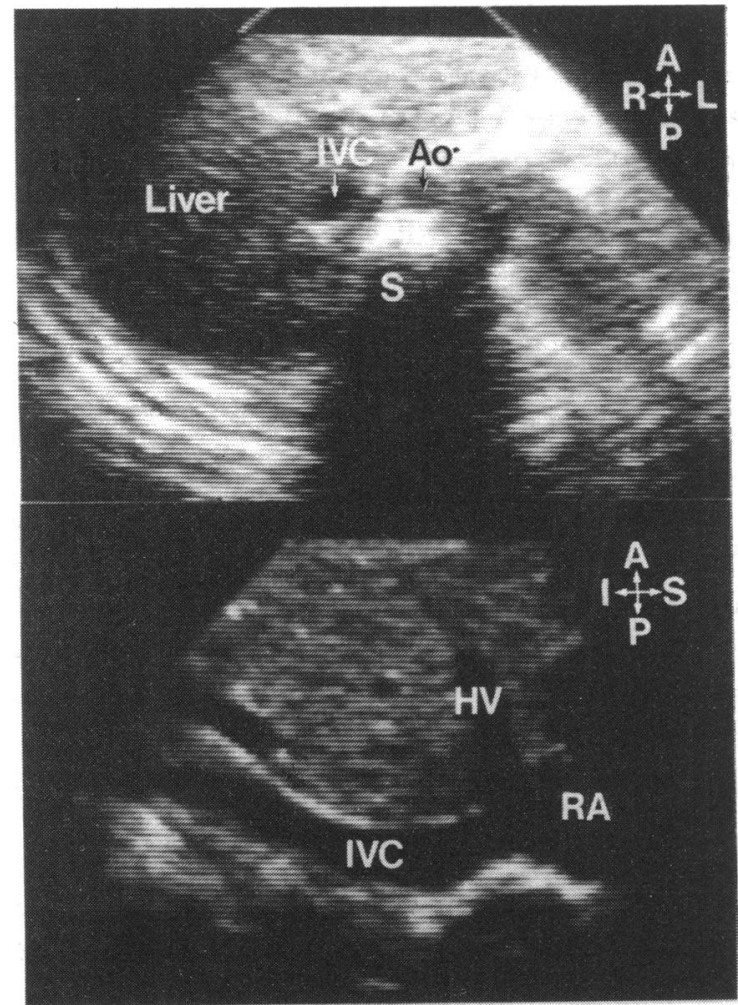

Fig. 1 Two dimensional echocardiographic appearance of situs solitus. In the short axis subcostal view (upper panel) the aorta (Ao) and inferior vena cava (IVC) are symmetrical with respect to the spine $(S)$ with the aorta to the left $(L)$ and the liver lateralised to the right $(R)$. In the long axis (lower panel) the inferior vena cava receives the hepatic veins $(H V)$ and connects to the right atrium $(R A)$. $A$, anterior; $I$, inferior; $P$, posterior; $S$, superior. of situs by either filtered beam high kilovoltage chest $x$-ray, ${ }^{10}$ surgery, or necropsy. ${ }^{13}$

Eight patients had necropsy confirmation of situs including three with left isomerism, and 39 patients had open heart surgery.

\section{Results}

DIAGNOSIS OF SITUS BY TWO DIMENSIONAL ECHOCARDIOGRAPHY

There was a typical appearance of the two dimensional echocardiographic short axis subcostal view of the abdomen in the patients with situs solitus (Fig. 1). At approximately the level of $\mathrm{T} 10$, the aorta lay to the left of the spine, being recognisable by its typical systemic arterial pulsation. The inferior vena cava was located opposite to the aorta on the right of the spine and was further identified by long axis subcostal views showing the right hepatic venous connection and inferior vena cava to the right atrial junction.

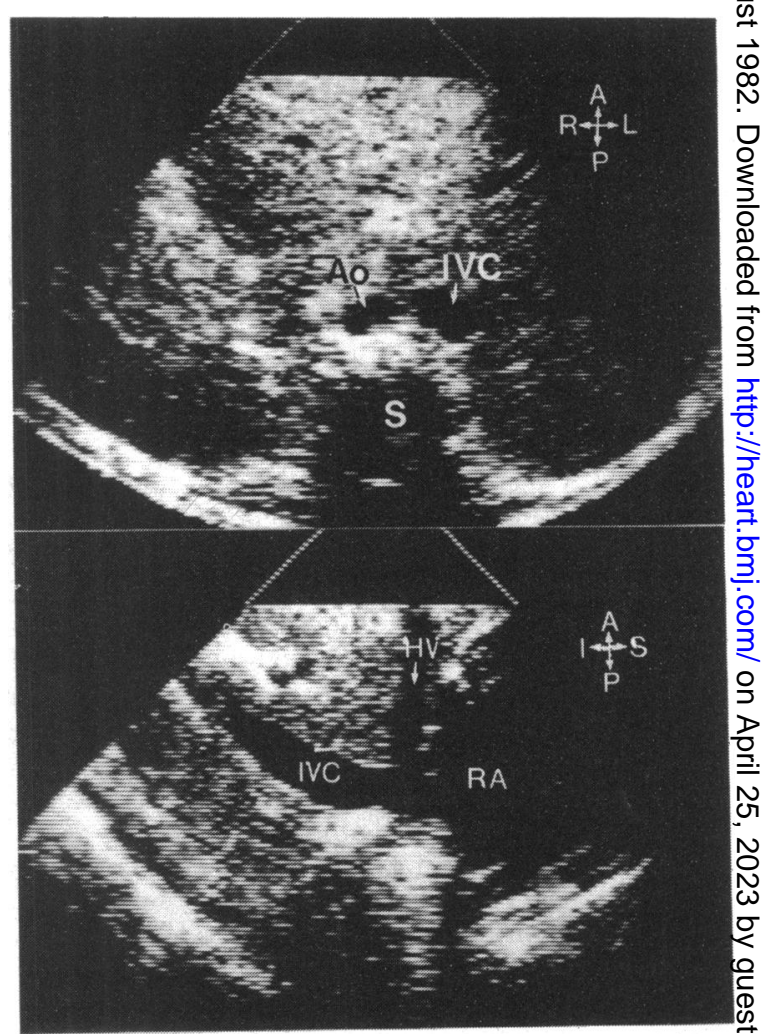

Fig. 2 Two dimensional echocardiographic appearance of situs inversus. A mirror image of the situs solitus pattern is present in the short axis view (upper panel) with the aorta $(A)$ on the right $\vec{D}$ $(R)$. The left sided inferior vena cava $(I V C)$ receives hepatic veins (HV) and connects to the morphological right atrium $(R A)$. (Abbreviations as in Fig. 1.)

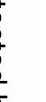


Table 1 Inferior vena cavalaorta position

\begin{tabular}{lllll}
\hline & $\begin{array}{l}\text { Inferior } \\
\text { vena caval } \\
\text { aorta } \\
\text { symmetry }\end{array}$ & $\begin{array}{l}\text { Inferior } \\
\text { vena caval } \\
\text { aorta } \\
\text { run } \\
\text { together }\end{array}$ & Other & Totals \\
\hline Inversus & 4 & 0 & 0 & \\
Right isomerism & 0 & 9 & 0 & 4 \\
Left isomerism & 0 & 1 & 15 & 16 \\
\hline
\end{tabular}

Patients with situs inversus were found to have a mirror image of the situs solitus pattern (Fig. 2), with the aorta to the right and the inferior vena cava to the left, both vessels again being symmetrically disposed with respect to the spine (Table 1 ). The hepatic venous connections and the inferior vena caval to right atrial junction also formed the mirror image of situs solitus with the hepatic veins connecting to the inferior vena cava or joining the atrium with the inferior vena cava.

Right or left isomerism could be diagnosed by the abnormal position of the inferior vena cava and aorta in the abdomen. These two entities could then be distinguished by the type of positional abnormality combined with the pattern of hepatic venous and inferior vena cava to right atrial connection.

In right isomerism, the aorta and inferior vena cava ran together at the subcostal level, with the aorta posterior, either to the right or left of the spine (Fig. 3 upper panels). The right hepatic vein connected to the inferior vena cava and could be visualised on the same side of the spine (Fig. 3 lower panels), (Table 1).

In left isomerism, the aorta was usually midline (13 patients), though it was to the right in two and to the left in one. No normal inferior vena cava was seen on this level. Instead azygos continuation of the inferior vena cava posterior to the aorta, either to the left or right of the spine, was present in 14 patients (Table 1; Fig. 4 upper panels). In two of these patients the azygos vein was not visualised and only the midline aorta could be seen. In the two remaining patients the suprarenal inferior vena cava connected to the inferior aspect of the atrium (left sided in one and right sided in one).

The crus of the diaphragm appeared as an echo free line close to the anticipated position of the normal inferior vena cava immediately below the cardiac

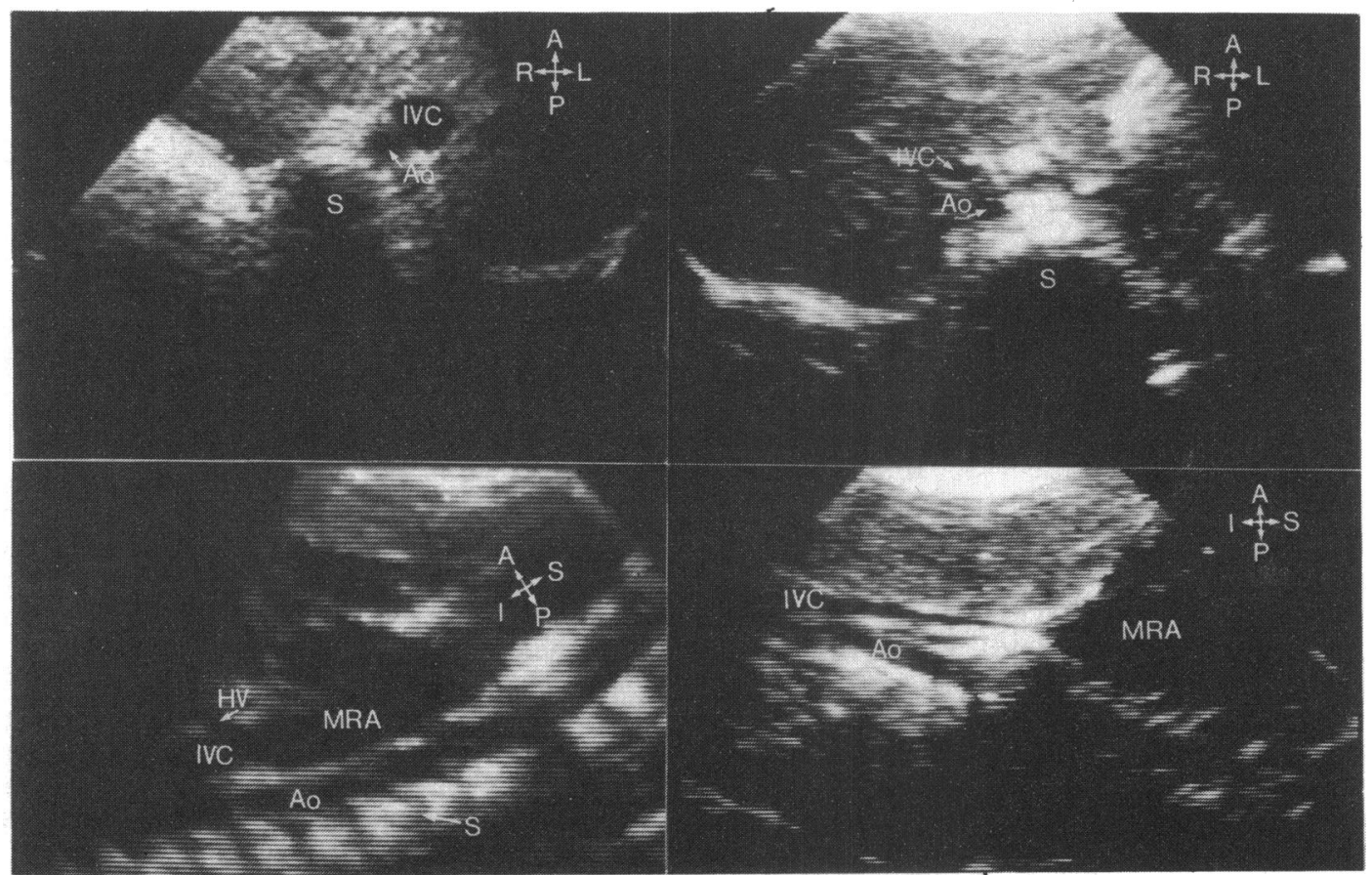

Fig. 3 Two dimensional echocardiographic appearance of right isomerism. The aorta (Ao) and inferior vena cava (IVC) run together with the inferior vena cava anterior and lateral either to the left $(L)$ (left upper panel) or to the right $(R)$ (right upper panel). The inferior vena cava receives hepatic venous connection $(H V)$ and connects to the inferior aspect of the morphological right atrium (MRA) (lower panels). Note that the inferior vena cava and aorta may be visualised in the same scan.

(Abbreviations as in Fig. 1.) 


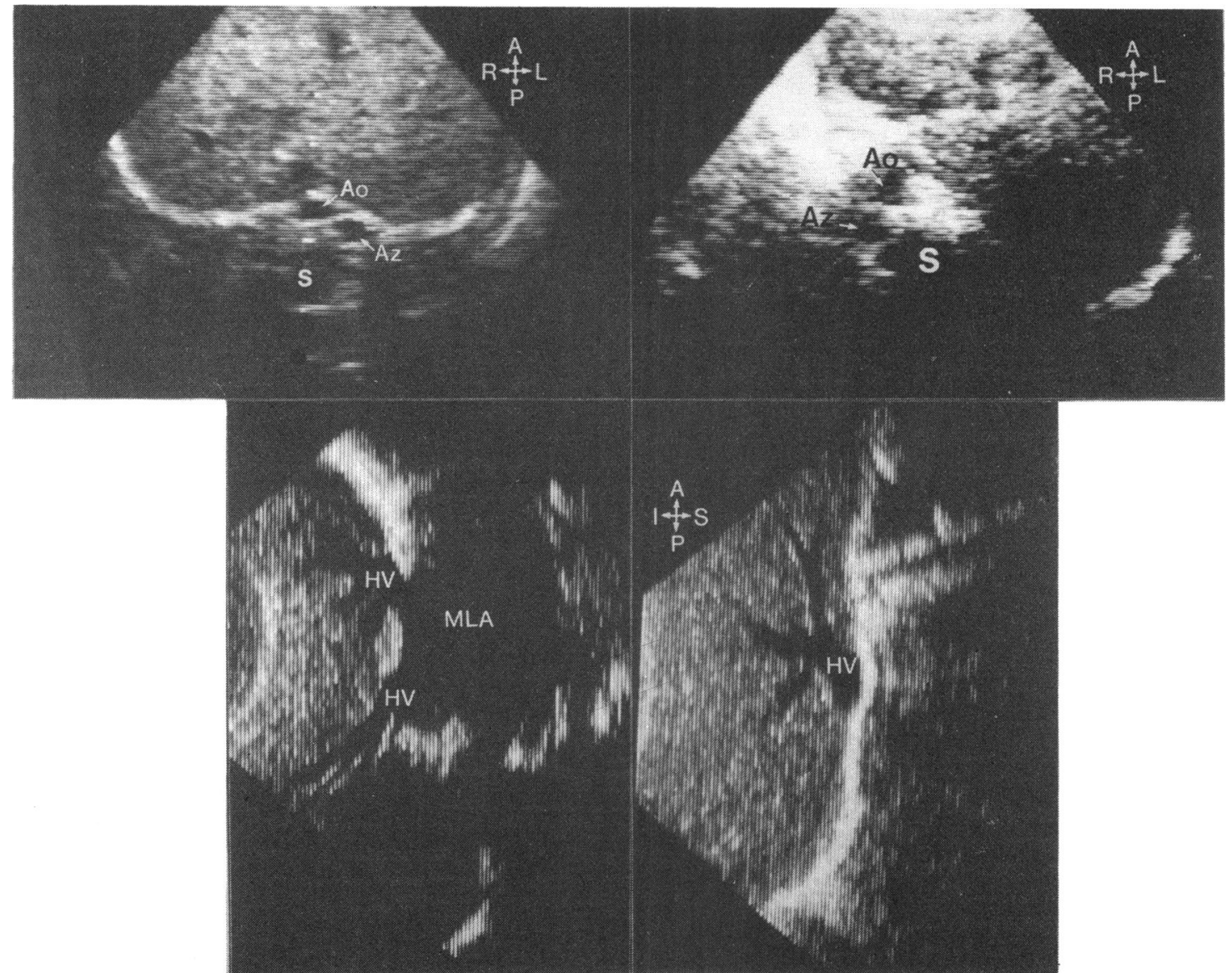

Fig. 4 Two dimensional echocardiographic appearance of left isomerism. The aorta $(A 0)$ is usually midline and an arygos continuation of the inferior vena cava $(A z)$ is often present located posterior $(P)$ either to the left $(L)$ or the right $(R)$ (upper panels). Total anomalous hepatic venous connection to a morphological left atrium $(M L A)$ is present either as two separate hepatic veins (HV) (left lower panel) or a single vein (right lower panel).

atria, but connected neither to the atria nor to any other vessels (Fig. 5). In all patients with left isomerism, including the two with the inferior vena cava entering the left or right sided atrium normally, one or two hepatic veins connected to the atrium separately from the other systemic venous return (Fig. 4 lower panels). The identity of the azygos continuation located posterior to the aorta was confirmed by echocardiographic contrast injection into the femoral vein in one patient.

\section{NORMAL VS ABNORMAL SITUS}

The wide range of congenital cardiac disease encountered in the 129 patients with situs solitus is shown in Table 2. These patients were compared with those with abnormal situs (inversus, right isomerism, or left isomerism) shown in Table 3. The ability of two dimensional echocardiography to separate these two groups is shown in Fig. 6 where abnormal situs is shown as a positive test and situs solitus as a negative test. There were no false negative diagnoses of abnormal situs and two false positives; these two patients both had exomphalos and malpositioned abdominal viscera. The usual pattern of situs solitus by two dimensional echocardiography was not present though atrial situs solitus was confirmed at necropsy in both. The intracardiac abnormalities were correctly predicted.

One patient had the typical symmetrical position of the inferior vena cava and aorta in the abdomen, but, in addition, a second venous structure was imaged to the right of and posterior to the aorta. This was cor- 


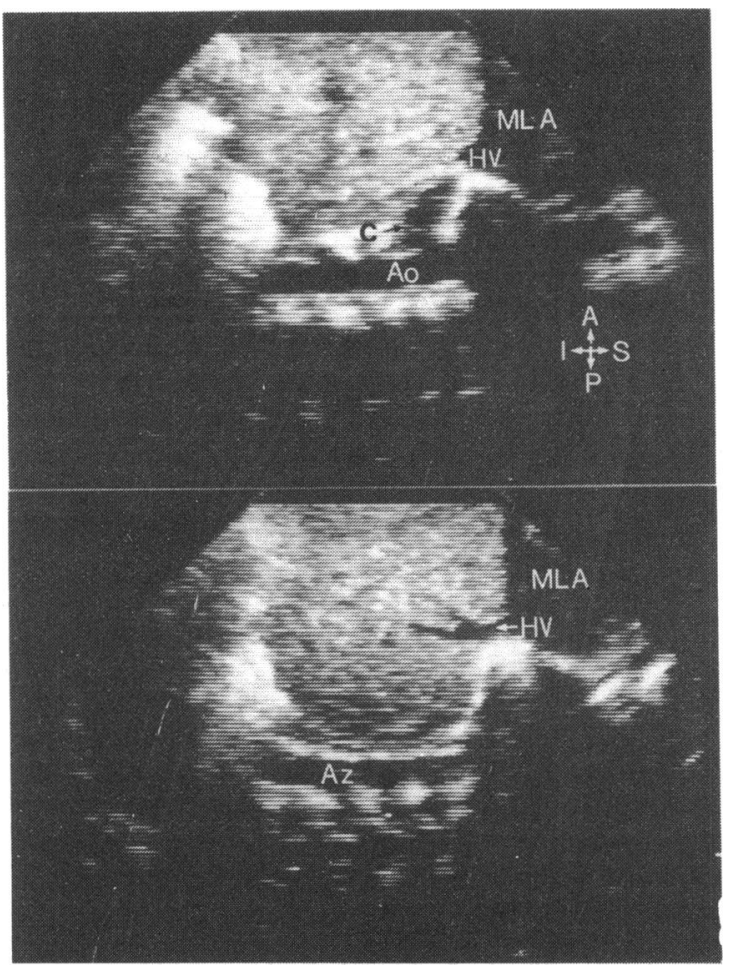

Fig. 5 Long axis subcostal scans in left isomerism should identify the aorta $(A O)$, crus of the diaphragm $(C)$, and hepatic venous connection $(H V)$ to the morphological left atrium (MLA) (upper panel). Scanning laterally the arygos continuation of the inferior vena cava $(A z)$ is visualised if present (lower panel).

Table 2 Two dimensional echocardiographic findings in 129 patients with situs solitus

\begin{tabular}{|c|c|c|c|c|}
\hline $\begin{array}{l}\text { Apex } \\
\text { Left }\end{array}$ & Right & $\begin{array}{l}\text { Aortic ar } \\
\text { Left }\end{array}$ & $\operatorname{arch}$ & Right \\
\hline 126 & 3 & 120 & 9 & 9 \\
\hline \multicolumn{2}{|c|}{$\begin{array}{l}\text { Atrioventricular connection } \\
\text { Concordant Discordant }\end{array}$} & \multirow{2}{*}{\multicolumn{2}{|c|}{$\begin{array}{ll}\text { Univentricular } \\
2 A V & \text { Absent } \\
2 A V & \text { valves } \\
3 & 10\end{array}$}} & CAVO \\
\hline \multicolumn{2}{|c|}{ Ventriculoarterial connection } & & & 1 \\
\hline $\begin{array}{l}\text { Concordant } \\
88\end{array}$ & $\begin{array}{l}\text { Discordant } \\
26\end{array}$ & $\begin{array}{l}\text { DORV } \\
9\end{array}$ & & $\begin{array}{l}\text { Single outlet } \\
6\end{array}$ \\
\hline
\end{tabular}

Isolated VSD, 31; persistent ductus arteriosus, 17 (isolated in eight); tetralogy of Fallot, 12; TAPVC, 10; DORV, 9; pulmonary stenosis, 8; aortic stenosis, 7; atrioventricular septal defect, 4; others, 15.

Abbreviations: AV, atrioventricular; CAVO, common atrioventricular valve orifice; DORV, double outlet right ventricle; TAPVC, total anomalous pulmonary venous connection; VSD, ventricular septal defect.

rectly predicted as situs solitus with right azygos continuation of the inferior vena cava plus the normal inferior vena cava to right atrial connection and was confirmed by angiography and at surgery.

Dextrocardia was present in three patients with situs solitus and six patients with abnormal situs. This did not present any difficulty in the segmental approach to diagnosis by two dimensional echocardiography. Care was necessary, however, to trace the inferior vena cava to right atrial connection correctly.

The liver was lateralised to the right in all patients with situs solitus except the two patients with exomphalos.

\section{ABNORMAL SITUS}

There were 29 patients with abnormal situs including four with situs inversus, nine with right isomerism, and 16 with left isomerism. The two dimensional echocardiographic criteria which could be easily obtained in all patients were analysed for the ability to separate the three types of abnormal situs.

\section{HEPATIC POSITION}

The hepatic position was lateralised in all with situs inversus (to the left), but did not discriminate left from right isomerism (Table 4).

A midline liver was present in 18 patients with atrial isomerism $(72 \%)$.

\section{SYSTEMIC VENOUS RETURN}

Although azygos continuation was present in one patient with situs solitus and is not the sine qua non of left isomerism, it was present in all but two patients (right sided in five, left sided in eight, and bilateral in one) (Table 5).

In the patient with left isomerism and bilateral azygos continuation the short axis scan of the abdomen showed the aorta to be midline with a posterior azygos vein on the left, an additional venous structure to the right, and no normal inferior vena cava entering the atrium. The azygos continuation could be traced to the junction with the ipsilateral superior vena cava or atrium in only two patients (Fig. 7).

The types of hepatic venous connection (Table 6) encountered were as follows.

(1) Normal, with the hepatic veins connecting to the inferior vena cava at or near the entry into the right atrium,

(2) Normal connection of some hepatic veins to the inferior vena cava with separate connection of other hepatic vein(s) directly to an atrium (partial anomalous hepatic venous connection) or,

(3) Separate hepatic venous connection directly to an atrium via one or more veins (total anomalous hepatic venous connection).

All of the patients with right isomerism had connection of some or all of the hepatic veins to the inferior vena cava which then connected to the right sided atrium while all of those with left isomerism had total anomalous hepatic venous connection. In the patients with a common atrium or only a small remnant of 
Table 3 Two dimensional echocardiographic findings in 29 patients with abnormal situs

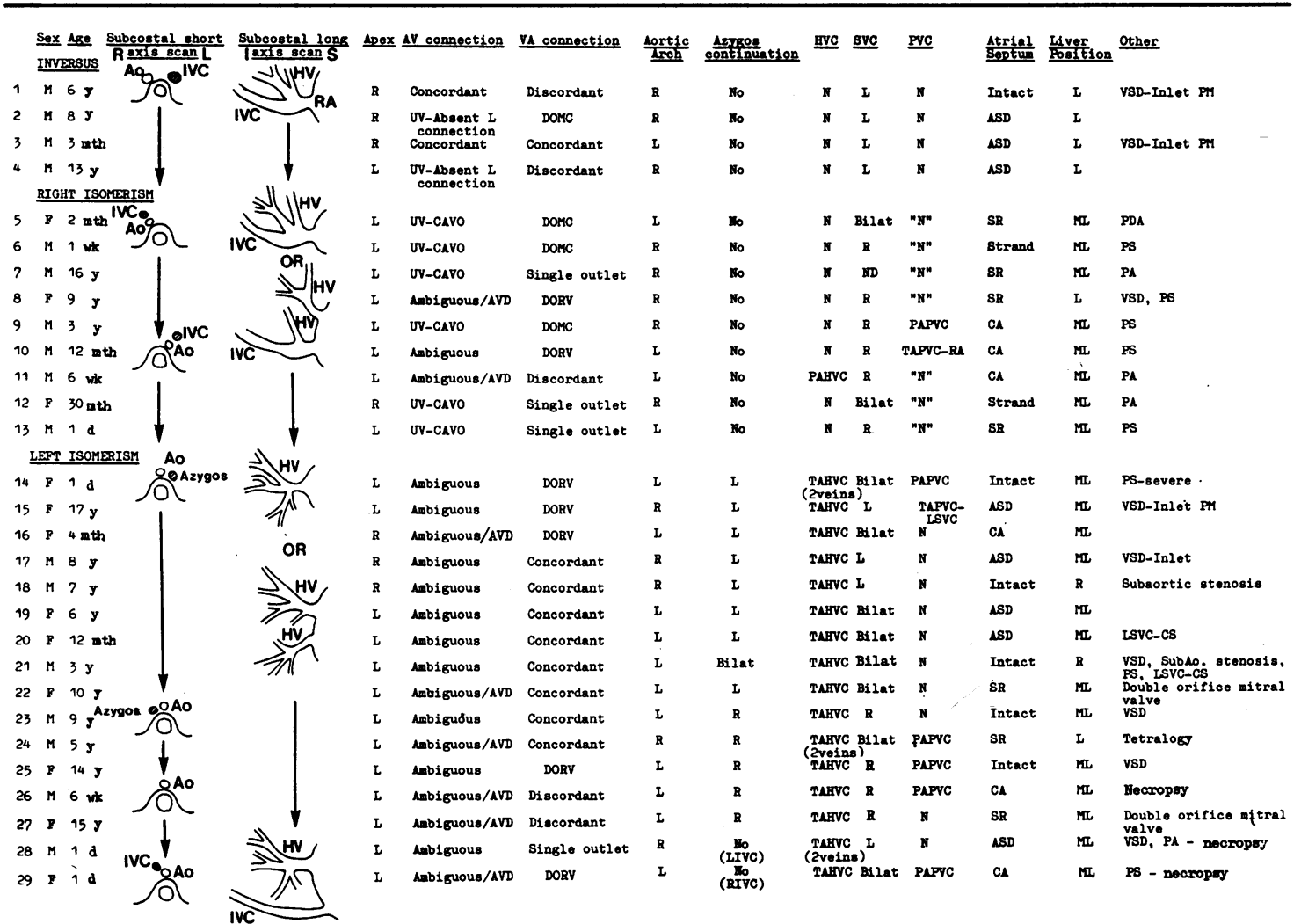

Abbreviations: Ao, aorta; AVD, atrioventricular septal defect (partial or complete); ASD, atrial septal defect at fossa ovalis; Bilat, bilateral; CA, common atrium; CAVO, common atrioventricular valve orifice; CS, coronary sinus; DOMC, double outlet main chamber; DORV, double outlet right ventricle; d, days; F, female; I, inferior; IVC, inferior vena cava; $L$, left; LIVC, left inferior vena cava; LSVC, left superior vena cava; $M$, male; ML, midline; mth, months; ND, not defined; N, normal; PAHVC, partial anomalous hepatic venous connection; PAPVC, partial anomalous pulmonary venous connection; PA, pulmonary atresia; PM, perimembranous; PVC, pulmonary venous connection; R, right; RIVC, right inferior vena cava; S, superior; SR, superior rim of interatrial septum; TAHVC, total anomalous hepatic venous connection; TAPVC, total anomalous pulmonary venous connection; UV, univentricular atrioventricular connection; VSD, ventricular septal defect; wk, weeks; y, years; " $N$ ", total anomalous pulmonary venous connection to a confluence which communicates directly with the left sided atrium in right isomerism.

atrial septum secundum it was difficult confidently to assign the hepatic venous connections to the right sided or left sided atrium.

Superior systemic venous connections (Table 7) were imaged in all patients. Bilateral superior venae cavae were present in 14 of the patients with atrial isomerism (43\%). In the patient with bilateral azygos continuation, the left superior vena cava received the azygos vein and then drained to the coronary sinus, whereas the right superior vena cava entered the right atrium directly.

In three of the 10 patients with bilateral superior vena cava, no bridging innominate vein was identified by two dimensional echocardiography or angiography.

A coronary sinus was identified by two dimensional echocardiography in all of the patients with situs inversus and in three patients with left isomerism (Fig. 8), two with a left superior vena cava connecting it.

PULMONARY VENOUS CONNECTION

Patterns of partial and total anomalous pulmonary venous connection were identified in the patients with atrial isomerism as well as in the normal subjects (Fig. N 9). Normal connection was present in all four patients with situs inversus (Table 8).

Seven patients with right isomerism had a pattern of total anomalous pulmonary venous connection to a $\stackrel{\oplus}{?}$ confluence which connected directly to the left sided $\square$ atrium, two had pulmonary veins connecting to both atria, and one had total anomalous pulmonary venous connection to the right sided atrium. Ten of the $\stackrel{\otimes}{\AA}$ patients with left isomerism had an entirely normal $\overline{0}$ 
Diagnosis of abnormal situs 2-D echo vs $x$-ray / necropsy

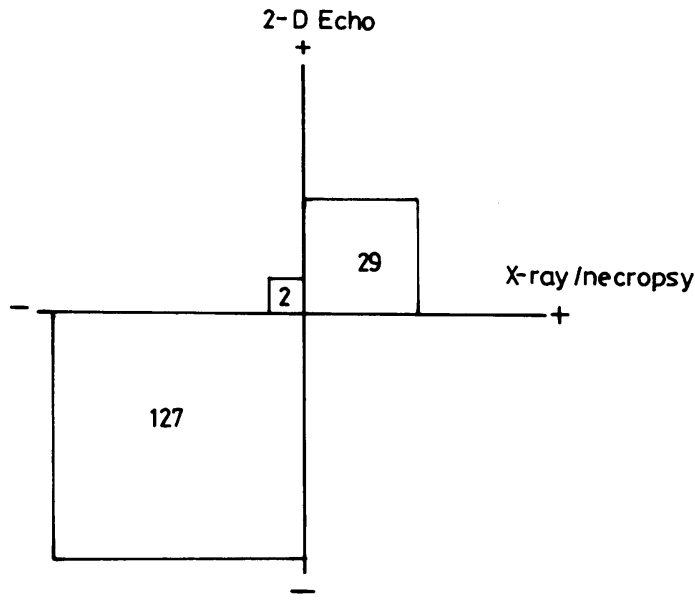

Fig. 6 Detection of abnormal situs by two dimensional echocardiography (2-D echo) compared with high kilovoltage chest x-ray necropsy findings. Twenty nine patients had abnormal situs (true positives) and 127 had situs solitus (true negatives). The two false positives were in patients with exomphalos and displacement of the abdominal viscera. Abnomal situs $=a$ positive test.

Table 4 Hepatic position

\begin{tabular}{lllcc}
\hline & Right & Left & Midline & Totals \\
\hline Inversus & 0 & 4 & 0 & 4 \\
Right isomerism & 2 & 2 & 5 & 9 \\
Left isomerism & 2 & 1 & 13 & 16 \\
\hline
\end{tabular}

Table 5 Azygos continuation

\begin{tabular}{llclc}
\hline & None & Unilateral & Bilateral & Totals \\
\hline Inversus & 4 & 0 & 0 & 4 \\
Right isomerism & 9 & 0 & 0 & 9 \\
Left isomerism & 2 & 13 & 1 & 16 \\
\hline
\end{tabular}

pulmonary venous connection. Thus, pulmonary venous connection did not aid in situs identification, though connection of pulmonary veins to a confluence behind the heart, and thence to a left sided atrium, should suggest right isomerism.

ATRIAL SEPTUM MORPHOLOGY

There were five patterns of atrial septum morphology which could be readily identified in patients with

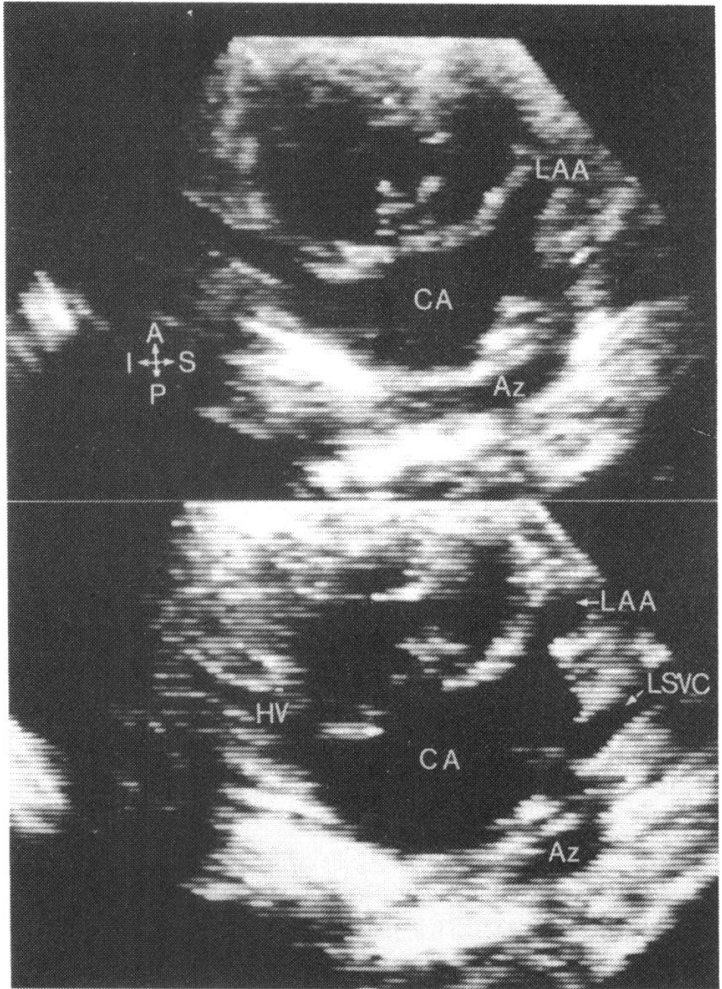

Fig. 7 Identification of arygos connection in a 3-month-old girl with left isomerism and a common atrioventricular valve orifice and common atrium (CA). The arygos (Az) joins the left superior aspect of the common atrium. A left superior vena cava (LSVC) enters separately (lower panel). Note the left atrial appendage (LAA) and hepatic venous connection (HV).

Table 6 Heptic venous connection

\begin{tabular}{lllcc}
\hline & Normal & PAHVC & TAHVC & Totals \\
\hline Inversus & 4 & 0 & 0 & 4 \\
Right isomerism & 8 & 1 & 0 & 9 \\
Left isomerism & 0 & 0 & 16 & 16 \\
\hline
\end{tabular}

PAHVC, partial anomalous venous connection (not all hepatic veins connect to the inferior vena cava); TAHVC, total anomalous hepatic venous connection.

abnormal situs (Table 9; Fig. 10).

The atrial strand seen in two patients with right isomerism is frequently found with this type of situs. ${ }^{13}$

We have succeeded in visualising the atrial appendages in some neonates (Fig. 11), including one patient with left isomerism. The recognition, however, of distinctive atrial appendage characteristics routinely is not yet feasible non-invasively. 
Table 7 Superior systemic venous connections

\begin{tabular}{|c|c|c|c|}
\hline & $R S V C$ & $L S V C$ & Bilateral SVC Totals \\
\hline $\begin{array}{l}\text { Inversus } \\
\text { Right isomerism } \\
\text { Left isomerism }\end{array}$ & $\begin{array}{l}0 \\
3 \\
4\end{array}$ & $\begin{array}{l}4 \\
0 \\
4\end{array}$ & $\begin{array}{r}4 \\
9 \\
16\end{array}$ \\
\hline
\end{tabular}

LSVC, left superior vena cava only; RSVC, right superior vena cava only; Bilateral SVC, superior vena cavae on the left and right with or without a bridging innominate vein.

\section{Discussion}

The sequential method of classifying congenital heart disease introduced by Van Praagh et al. ${ }^{2}$ is based on a knowledge of atrial situs. This approach has been extended from descriptions of pathological material to the diagnosis of cardiac abnormalities diagnosed preoperatively. Angiography has been used to do this in the past and the separation of atrial situs into solitus, inversus, and ambiguus has been attempted. ${ }^{14} 15$ The close correlation of bronchial and atrial situs has allowed situs to be determined with a chest radiograph though special techniques are necessary in infants and young children. ${ }^{10}$

M-mode echocardiography has been applied to sequential cardiac diagnosis ${ }^{16} 17$ but is severely limited and of no use in determining atrial situs.

Many correlates exist which might be used to predict the atrial situs. These include: (1) splenic status 6 18; (2) lung lobation; (3) position of abdominal viscera, which has been shown to lack accuracy ${ }^{13}$; (4) bronchial morphology which has a high correlation with atrial situs ${ }^{13} 19$ and has the advantage of being noninvasive.

Other correlates which have been studied include: (5) pulmonary venous connection; (6) presence or absence of coronary sinus ${ }^{13}$; (7) pulmonary artery morphology';
(8) systemic venous connection ${ }^{14}$; and (9) electrocardiogram $P$ wave axis. ${ }^{20}$ Becker and Anderson ${ }^{21}$ suggested that, (10) hepatic atrial connection may be uniform in right isomerism. Elliott et al. ${ }^{22}$ showed that forward venous angiography was valuable in diagnosing right isomerism and described (11) position of the inferior vena cava and aorta as "the aorta seeking out" the inferior vena cava in the abdomen.

Two dimensional echocardiography is an excellent method of imaging intra- and extracardiac thoracic structures and is equally suited for displaying denser structures such as the liver. Therefore, we used two dimensional echocardiography to assess (3), (5), (6), $(8),(10)$, and (11) to predict atrial situs thereby.

This investigation extends the non-invasive diagnosis of situs in two important directions. Firstly, the position of the inferior vena cava and aorta alone has been shown reliably to separate those patients with situs solitus from those with either situs inversus or atrial isomerism (situs ambiguus) and to be specific for situs inversus. Right isomerism has a typical pattern by two dimensional echocardiography using this criterion and would have been adequate on its own apart from one exception in this study. All previous detailed studies of situs have lacked information concerning the in vivo position of the great vessels in the abdomen. Tomographic methods such as computerised tomographic scans and two dimensional echocardiography now allow-non-invasive determination of these details which have previously been recognised to be important indicators of situs. ${ }^{22}$

The level of the diaphragm (approximately T10) is an important location for making these observations. Between the level of the renal veins and this location the suprarenal segment of the inferior vena cava (deriving from the subcardinal system) normally connects to the hepatic veins and the atrium. If there is

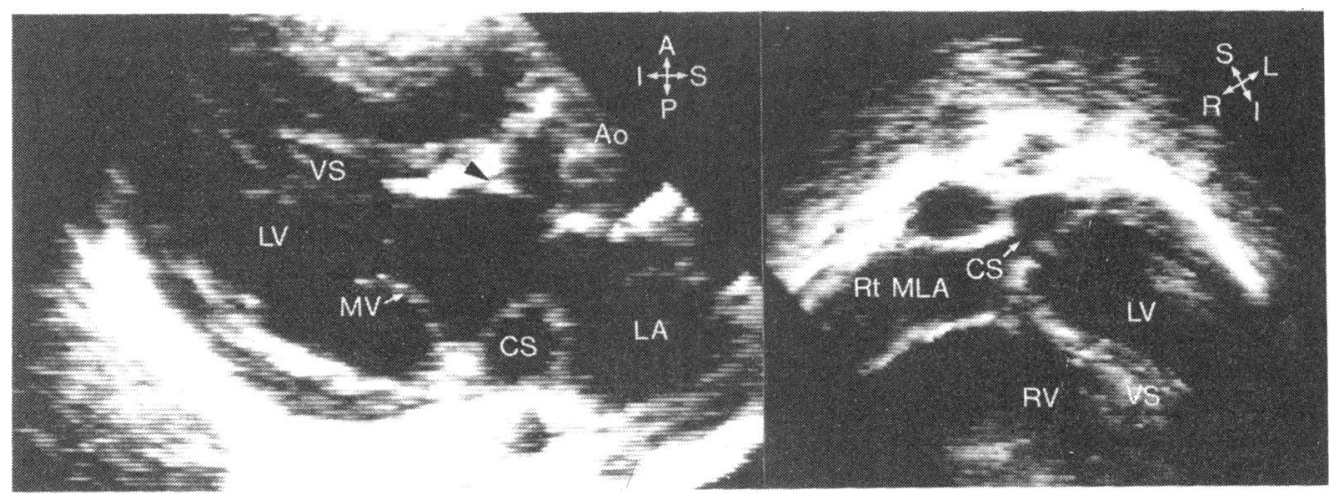

Fig. 8 Dilated coronary sinus (CS) in a 3-year-old boy with left isomerism and bilateral asygos continuation (case 21). Note the presence of subaortic stenosis (left panel). The coronary sinus to right sided morphological left atrium $(R t M L A)$ junction (right panel) was present and did not aid in separating left isomerism from situs solitus. LA, left atrium; $L V$, left ventricle; $M V$, mitral valve; $R V$, right ventricle; $V S$, ventricular septum. 


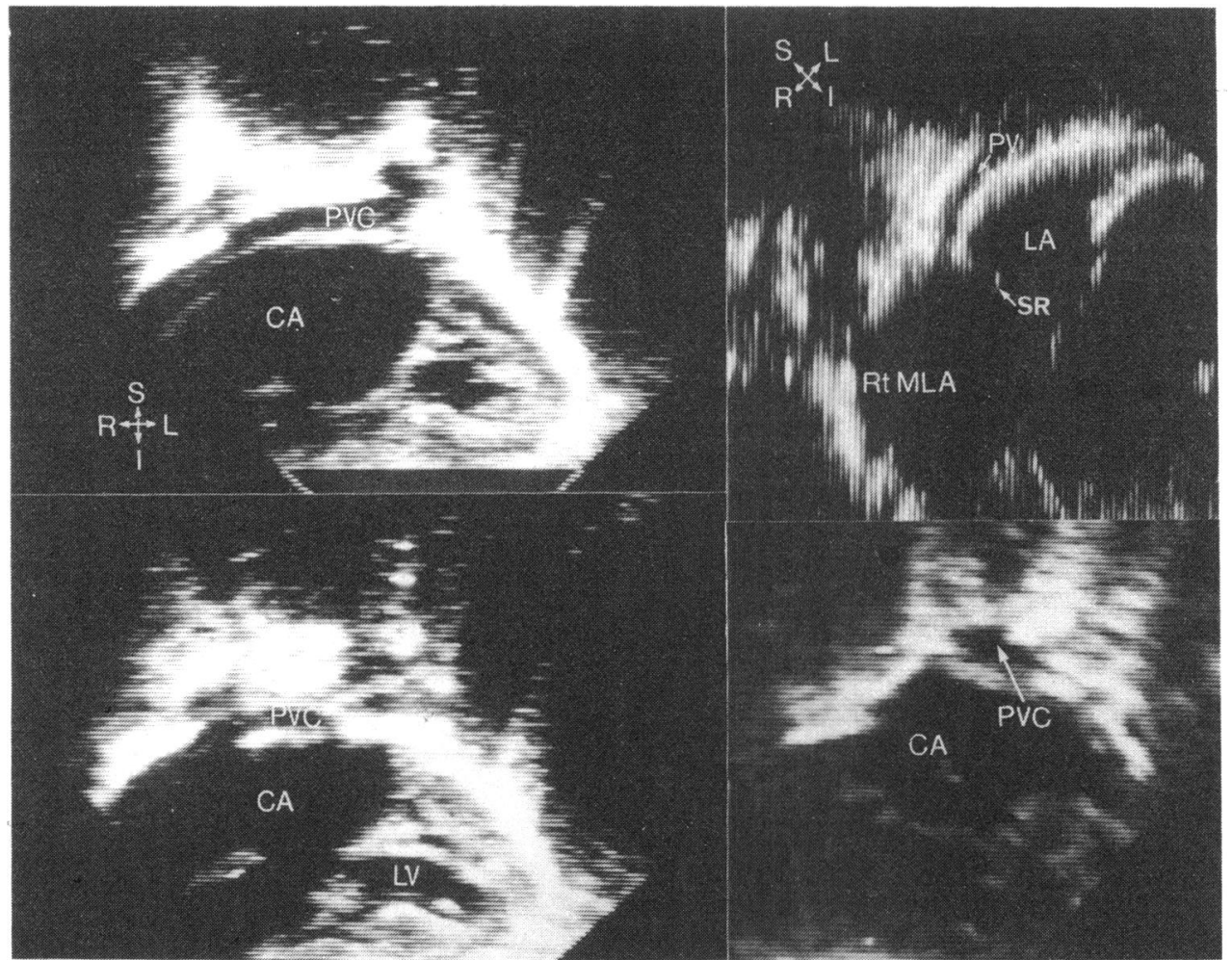

Fig. 9 Examples of total anomalous pulmonary venous connection to the right side of a common atrium $(C A)$ in right isomerism (left upper and lower panels). Partial anomalous pulmonary venous connection of the left pulmonary veins (PV) to the right atrium in left isomerism (right upper panel). A pulmonary venous confluence $(P V C)$ (right lower panel) was present in many patients with right isomerism even when the drainage was to the lefi sided atrium. Rt MLA, right sided morphological left atrium; $S R$, superior rim; $L V$, left ventricle.

Table 8 Pulmonary venous connection

\begin{tabular}{lcllc}
\hline & Normal & PAPVC & TAPVC & Totals \\
\hline Normal & 4 & 0 & 0 & 4 \\
Right isomerism & 0 & 1 & $8^{\star}$ & 9 \\
Left isomerism & 10 & 5 & 1 & 16 \\
\hline
\end{tabular}

* Seven connecting to left sided morphological right atrium. PAPVC, partial anomalous pulmonary venous connection; TAPVC, total anomalous pulmonary venous connection.

azygos continuation of the inferior vena cava (deriving from the supracardinal system) it will often enter the thorax with the aorta through the aortic hiatus of the diaphragm. ${ }^{23}$ The azygos continuation was detected at this level in nearly all patients in this study.

Secondly, the patterns of the inferior vena cava connection to the atrium and hepatic venous connection aided in separating the rare patient with situs solitus and azygos continuation from those with left isomerism. In addition, though two patients with left isomerism had no azygos continuation and the aorta and inferior vena cava ran together in one, there was a totally separate hepatic venous connection. Therefore, total anomalous hepatic venous connection was specific for left isomerism.

The complexity of the systemic venous anomalies in atrial isomerism serves to support the view that not all patients fall into the category of either solitus or inversus. These data strongly support the view that there are four types of situs and that certain aspects of systemic venous return are typical for each type including those with atrial isomerism. For example, all patients with right isomerism had at least a right superior vena cava plus a normal "right" type of hepatic venous and inferior vena cava to right atrial connection. Partial anomalous hepatic venous connection is known to occur in right isomerism ${ }^{13}$ and was present in one patient, but total anomalous hepatic venous connection was not seen. We have observed that the hepatic venous morphology is typical of a right hepatic vein in right isomerism, situs solitus, and situs inversus but is atypical in left isomerism. 
Table 9 Atrial septum morphology

\begin{tabular}{lllllll}
\hline & PFO hintact & Secundum ASD & Common atrium & Superior rim & Strand & Totals \\
\hline Inversus & 1 & 3 & 0 & 0 & 0 & 4 \\
Right isomerism & 0 & 0 & 3 & 4 & 2 & 9 \\
Left isomerism & 5 & 5 & 3 & 3 & 0 & 16 \\
\hline
\end{tabular}

ASD, atrial septal defect; PFO, patent foramen ovale, Common atrium, superior rim, and strand all occurred with atrioventricular septal defects.

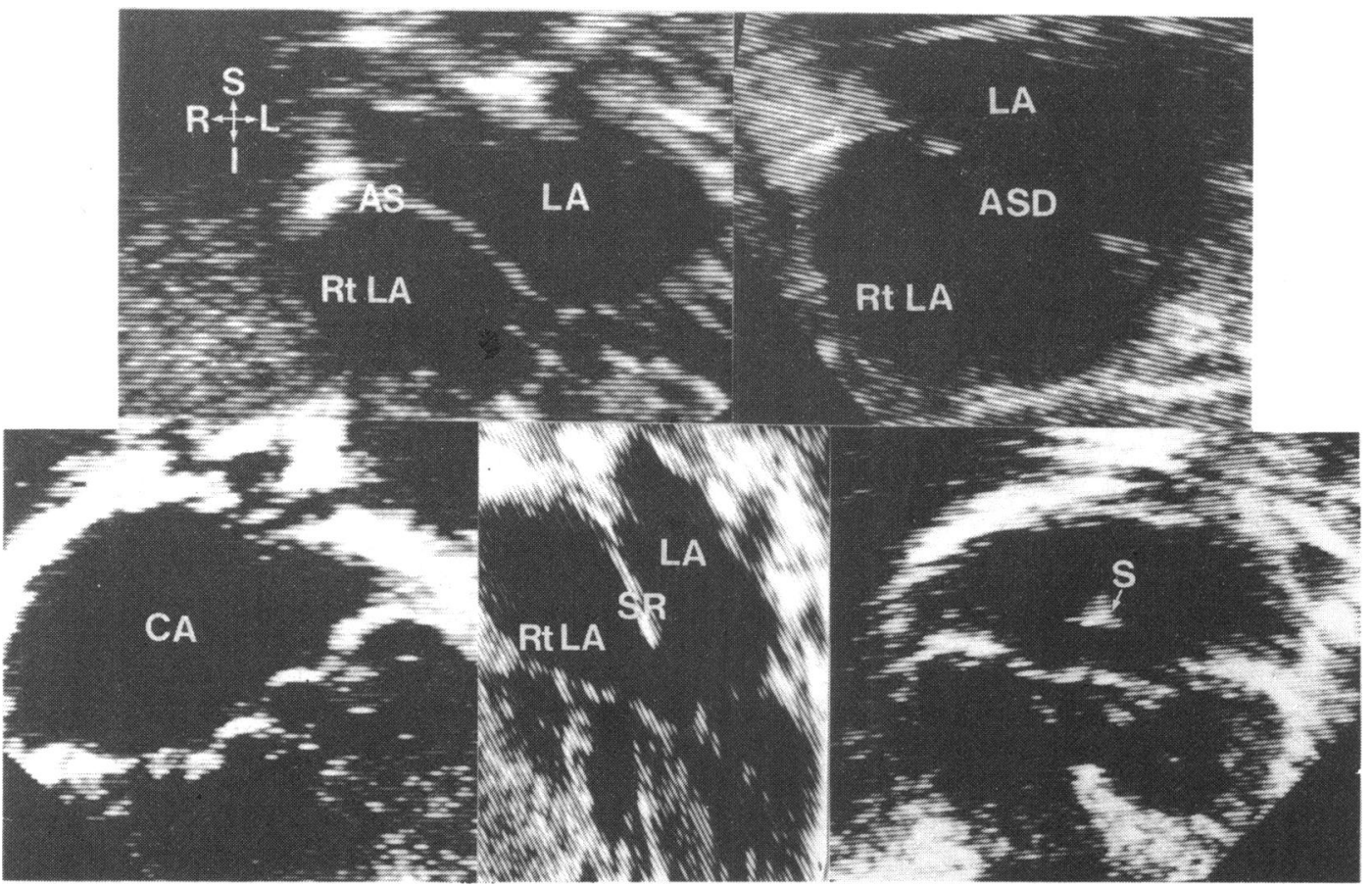

Fig. 10 Five types of atrial septum (AS) morphology found in atrial isomerism. Intact septum (left upper), secundum atrial defect (ASD) (right upper), common atrium (CA) (left lower), superior rim (SR) of atrial septum (middle lower), and strand (S) (right lower). LA, lefi atrium; Rt LA, right sided morphological left atrium.

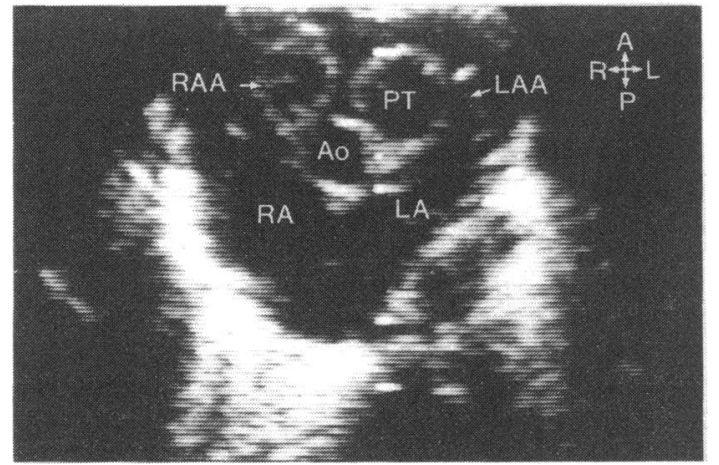

Fig. 11 Two dimensional echocardiographic appearance of atrial appendages in situs solitus. Note the broad, blunt appearance of the right atrial appendage (RAA) and narrow pointed appearance of the left atrial appendage (LAA). PT, pulmonary trunk.
We do not know if all patients with situs solitus and azygos continuation also have a small or rudimentary remnant of inferior vena cava which connects in the normal way after receiving hepatic venous connection. The patient shown in Fig. 12 with situs solitus and a normal inferior vena cava together with hemiazygos continuation illustrates this possibility. Though we have not examined this patient by two dimensional echocardiography this represents one situation where subcostal scans should identify the inferior vena cava but, if it were hypoplastic, a false positive diagnosis of left isomerism might be made. We continue to use the high kilovoltage chest radiograph to diagnose situs in such questionable cases.

The prevalence of abnormalities of situs is not well defined because not all are associated with congenital cardiac defects which, in the past, have led to investigative procedures. Based on the knowledge we have 


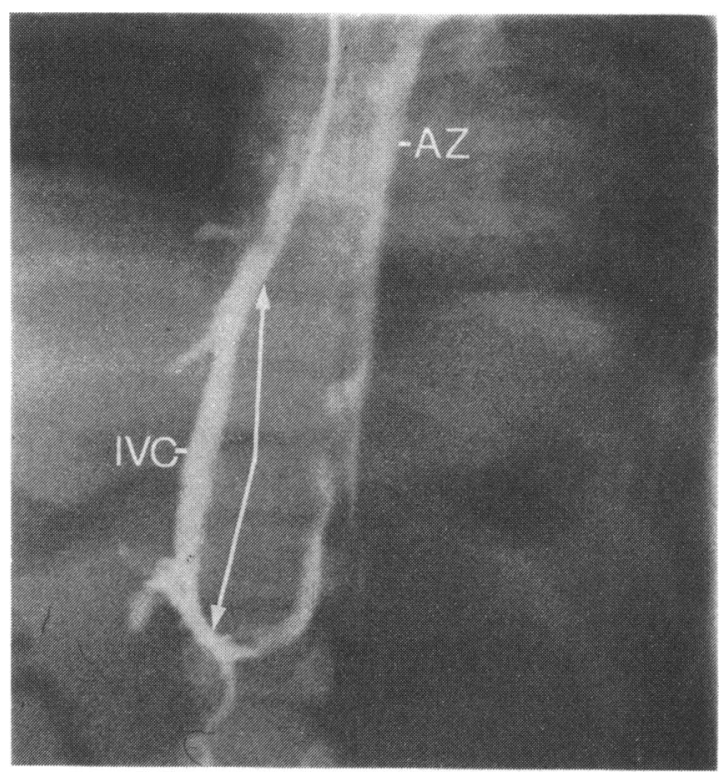

Fig. 12 Angiographic appearance of suprarenal inferior vena cava (IVC) (arrows) and hemiarygos continuation of the IVC $(A Z)$ in a patient with situs solitus. Atresia or severe hypoplasia of the region indicated could mimic left isomerism.

gained in this investigation we would predict that more cases of abnormal situs will be recognised with the aid of two dimensional echocardiography. Two patients in the series whose situs was thought to be solitus have been followed in our clinic for relatively minor congenital defects. One had had previous angiography and open heart surgery yet filter films of both bronchi showed left isomerism in both. Comparing previously reported pathological series of isomerism, one finds a ratio of nearly 3:1 for right/left isomerism in necropsy material, whereas the ratio is nearly reversed when the diagnosis is made before death. This suggests that the prevalence of left isomerism is much higher than right isomerism, as found in life by Partridge et al..$^{8}$ and Deanfield and colleagues. ${ }^{10}$ This undoubtedly reflects the poorer prognosis of right isomerism, and the resultant higher incidence of hospital necropsy.

We suggest a two dimensional echocardiographic approach to the diagnosis of situs as outlined in Fig. 13. Assessment of the aorta/inferior vena cava relation in the subcostal position immediately separates those patients with symmetric appearance of the great vessels, who have situs solitus or inversus, from those with an abnormal appearance. If the aorta and inferior vena cava run together, then atrial isomerism is almost certainly present unless some other condition such as exomphalos exists to disturb abdominal great vessel relations. Long axis subcostal views are then used further to identify the venous structures and to examine the hepatic venous connection. If there is total anomalous hepatic venous return, the diagnosis is left isomerism. Most of these patients will have an interrupted inferior vena cava. If there is not total anomalous hepatic venous return the diagnosis is almost certainly right isomerism or lateralised situs, which are distinguished as already described. Further studies in a larger number of patients will be required to answer the question of whether the hepatic veins ever connect to the inferior vena cava in patients with left isomerism. If only the aorta can be visualised and the hepatic veins all appear to connect anomalously, then the most likely diagnosis is left isomerism with azygos continuation, though we would use the bronchial morphology as an aid in such circumstances.

We thank Dr F Arensman, Harefield Hospital, for permission to examine case 4 .

Dr J C Huhta was a British Heart Foundation Overseas Fellow. Professor F J Macartney is supported by the Vandervell and British Heart Foundations.

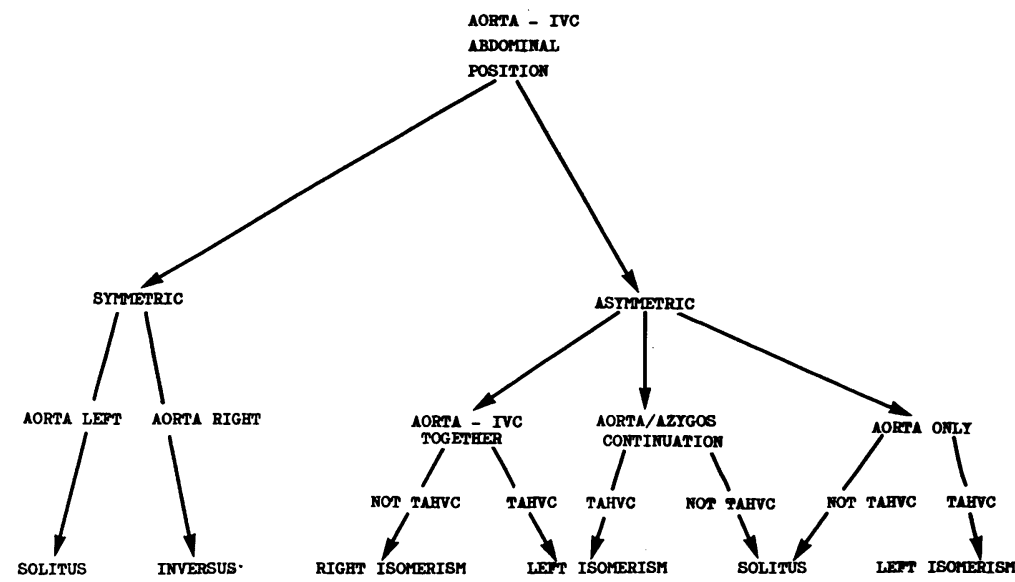

Fig. 13 Two dimensional echocardiographic approach to the diagnosis of situs based on long and short axis subcostal views. Abnormal situs is detected by the asymmetry of the short axis view and further delineation is possible based on the presence or absence of total anomalous hepatic venous connection (TAHVC). 


\section{References}

1 Lev M. Pathologic diagnosis of positional variations in cardiac chambers in congenital heart disease. Lab Invest 1954; 3: 71-82.

2 Van Praagh $R$, Van Praagh S, Vlad P, Keith JD. Anatomic types of congenital dextrocardia. Diagnostic and embryologic implications. Am $\mathcal{f}$ Cardiol 1964; 13: 510-31.

3 Stanger P, Rudolph AM, Edwards JE. Cardiac malpositions. An overview based on study of sixty-five necropsy specimens. Circulation 1977; 56: 159-72.

4 Macartney FJ, Partridge JB, Shinebourne EA, Tynan $M J$, Anderson $R H$. Identification of atrial situs. In: Anderson RH, Shinebourne EA, eds. Paediatric cardiology 1977. Edinburgh: Churchill Livingstone, 1978: 1626.

5 Brandt HM, Liebow AA. Right pulmonary isomerism associated with venous, splenic and other anomalies. $L a b$ Invest 1958; 7: 469-504.

6 Moller JH, Nakib A, Anderson RC, Edwards JE. Congenital cardiac disease associated with polysplenia. Circulation 1967; 36: 789-99.

7 Van Mierop LHS, Wiglesworth FW. Isomerism of the cardiac atria in the asplenia syndrome. Lab Invest 1962; 11: 1303-15.

8 Partridge JB, Scott O, Deverall PB, Macartney FJ. Visualization and measurement of the main bronchi by tomography as an objective indicator of thoracic situs in congenital heart disease. Circulation 1975; 51: 188-96.

9 Soto B, Pacifico AD, Souza AS Jr, Bargeron LM Jr, Ermocilla R, Tonkin IL. Identification of thoracic isom-

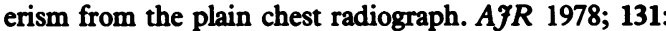
995-1002.

10 Deanfield JE, Leanage $R$, Stroobant J, Chrispin AR, Taylor JFN, Macartney FJ. Use of high kilovoltage filtered beam radiographs for detection of bronchial situs in infants and young children. Br Heart $\mathcal{F} 1980 ; 44$ : 577-83.

11 Tajik AJ, Seward JB, Hagler DJ, Mair DD, Lie JT. Two dimensional real-time ultrasonic imaging of the heart and great vessels. Technique, image orientation, structure identification, and validation. Mayo Clin Proc 1978; 53: 271-303.

12 Tynan MJ, Becker AE, Macartney FJ, Quero-Jimenez M, Shinebourne EA, Anderson RH. Nomenclature and classification of congenital heart disease. Br Heart $\mathcal{F} 1979$; 41: 544-53.

13 Macartney FJ, Zuberbuhler JR, Anderson RH. Morphological considerations pertaining to recognition of atrial isomerism. Consequences for sequential chamber localisation. Br Heart f 1980; 44: 657-67.

14 Squarcia U, Ritter DG, Kincaid OW. Dextrocardia angiocardiographic study and classification. Am $\mathcal{F}$ Cardiol 1973; 32: 965-77.

15 Brandt PWT, Calder AL. Cardiac connexions: the segmental approach to radiologic diagnosis in congenital heart disease. Curr Probl Diagn Radiol 1977; 7: 1-35.

16 Solinger R, Elbl F, Minhas K. Deductive echocardiographic analysis in infants with congenital heart disease. Circulation 1974; 50: 1072-96.

17 Meyer RA, Schwartz DC, Covitz W, Kaplan S. Echocardiographic assessment of cardiac malposition. Am $\mathcal{Y}$ Cardiol 1974; 33: 896-903.

18 Van Mierop LHS, Gessner IH, Schiebler GL. Asplenia and polysplenia syndrome. Birth Defects 1972; Vol. 8, no. 5: $36-44$.

19 Van Mierop LHS, Eisen S, Schiebler GL. The radiographic appearance of the tracheobronchial tree as an indicator of visceral situs. Am $\mathcal{F}$ Cardiol 1970; 26: 432-5.

20 Dickinson DF, Wilkinson JL, Anderson KR, Smith A, Ho SY, Anderson RH. The cardiac conduction system in situs ambiguus. Circulation 1979; 59: 879-85.

21 Becker AE, Anderson RH. Atrial isomerism ('situs ambiguus'). In: Pathology of congenital heart disease. London: Butterworths, 1981: 221-4.

22 Elliott LP, Cramer GG, Amplatz K. The anomalous relationship of the inferior vena cava and abdominal aorta as a specific angiocardiographic sign in asplenia. Radiology 1966; 87: 859-63.

23 Lucas RV Jr, Schmidt RE. Anomalous venous connections, pulmonary and systemic. In: Moss AJ, Adams FH, Emmanouilides GC, eds. Heart disease in infants, children and adolescents. 2nd ed. Baltimore: Williams \& Wilkins, 1977: 437-70.

Requests for reprints to Professor F J Macartney, The Hospital for Sick Children, Great Ormond Street, London WCIN 3JH. 